\title{
Simulation of queue length on Amplas Entrance Toll before and after the ramp off development with Vissim software
}

\author{
Medis Surbakti ${ }^{1, *}$, Tadeus Satria ${ }^{1}$ \\ ${ }^{1}$ University of North Sumatera, Department of Civil Engineering, Medan, Indonesia
}

\begin{abstract}
In 2016 Medan City administration built on off ramp at Amplas fly over, where this ramp off directly to toll booth Amplas. The faster the time needs to get to the toll booth enables the rate of arrival vehicles that impact with increasing queue length. The purpose of this study is to know the length of the queue at Amplas toll booth before and after ramp off construction with queue theory method and vissim softwaremodelings. Data acquired by recording the activities at the research site in the form of vehicles volume. The queue length obtained from the queue method with average service time 7 seconds is 6,212 meter while the result using VISSIM software is 11,988 meter. From the VISSIM software models also obtained that the length of queue after the construction of the ramp off increases compared before the construction of ramp off, from 6,67 meter to 11,988 metre.
\end{abstract}

\section{Preface}

\subsection{Background}

The increasing demand for vehicle traffic services accompanies the development of the region in Medan City. This influence has been anticipated by efforts to strengthen the road network. One of the anticipations is the construction of highway toll roads. In this case PT. Jasa Marga should provide higher reliability and ensure that vehicle operations are better than alternative roads $[1,2]$. Given the toll road function must provide services in the form of smooth flow of vehicles without any obstacles, then the problems causing congestion need to be investigated. One of the factors that often cause congestion is the process of queuing at toll gates [3-5]. At the time of processing at toll booths the toll road users are required to collect entrance tickets at the entrance gate and pay the toll at the exit gate. Thus the duration of processing at the toll gate affects the smooth flow of the vehicle. In the real fact, long queues of vehicles at toll booths are often found mainly during rush hours. Some previous researches on the length of queues at toll booths indicate that the queue at toll booths occurs due to the arrival rate (flow rate) of vehicles going to toll booths is not balanced with the service level in the service substations. One of them occurs at the toll

* Corresponding author: medissurbakti@yahoo.com 
booth where the queues are frequent. In addition to connecting the city of Medan other cities such as Tj.Morawa and Deli Serdang, Amplas toll booth is the fastest path to Kualanamo Airport located in Deli Serdang. This makes people more interested in using toll roads than using alternative roads. In 2016, the government made the on off ramp development on the fly over Amplas, where the ramp off will go directly to the toll booth Amplas so that people who want to go to the toll of Amplas from the direction of SM. Raja road does not need to cross intersection [6-7]. The quicker the time it takes the driver to go to the toll booth allows for an increase in arrival rate which ultimately impacts with increasing queue length. For that I as a researcher wanted to review whether there are real effects that occur after the construction of the ramp off against the length of the queue at the toll booth Amplas.

\subsection{Formulating of the problem}

The How the impact of ramp-off construction on the Amplas fly over the queue length at the entrance toll of Amplas?.

\subsection{Research purpose}

1. To determine the length of the queue at the toll booth before and after the construction of the ramp off on the amplas fly over

2. To determine the optimum service time at the toll booth Amplas

3. To analyze the capacity and service level of the toll gate entering the Amplas by using the existing system. The results of the analysis are used to determine whether at the toll gate Amplas can accommodate vehicles that come according to Minimum Service Standards (MSS)

4. Provide advice in the form of policy to reduce the length of the queue at the toll booth Amplas, where the suggestion is given in the form of simulation of queue length at the tollgate Amplas by using VISSIM software.

\section{Literature review}

\subsection{Queuing theory}

Queue occurs because the traffic flow process is disrupted by a service activity traversed. This theory provides important information needed to solve the above problems by forecasting various characteristics with queuing systems.

\subsection{Calling Population}

The pattern of arrival has unlimited and unlimited nature, of which the infinite nature is generally also random if the arrival is assumed to occur at a constant mean velocity and free of each other is called the Poisson probability distribution. The probability and arrival in time $\mathrm{T}$ is determined by the formula:

$$
P(r, T)=\frac{e^{-\lambda T}(\lambda T)^{r}}{r !}
$$

Where:

$\lambda=$ average unified arrival time 
$\mathrm{T} \quad=$ time periode

e $\quad=$ natural logarithm number $(\mathrm{e}=2.7182818)$

$\mathrm{r} \quad=$ the number of arrivals in timeT; $(\mathrm{n}=0,1,2 \ldots)$

$\mathrm{P}(\mathrm{r}, \mathrm{T}) \quad=$ probabilty $\mathrm{n}$ arrival in time $\mathrm{T}$

If the arrival follows the Poisson Distribution it can be shown mathematically that the interception will be distributed according to the exponential distribution

$$
P(s \leq t)=e^{-\lambda t}, 0 \leq t \leq \infty
$$

Where:

$\mathrm{P}(\mathrm{s} \leq \mathrm{t}) \quad=$ probability where time is between arrival time unity

$\mathrm{T}=$ average time in system (seconds)

\subsection{Level of service}

The service level $(\mu)$ is the number of vehicles / persons that can be served by one service place in a given time unit. In addition to the level of service, it is also known as Time of Service (WP) which is defined as the time required by a single shelter to be able to serve one vehicle / person. Usually expressed in units of minutes / vehicles or minutes / people, so it can be concluded that $[3,4]$ :

$$
W P=\frac{1}{\mu}
$$

Also known as $\rho$ notation is defined as follows

$$
\rho=\frac{\lambda}{\mu}<1
$$

If the value is $\rho>1$, this means that the arrival rate is greater than the rate of service. If this happens, then certainly there will be a queue that will always increase in length (infinity)

\subsection{Discipline queue FIFO (Fisrt In First Out)}

For an example FIFO discipline is the queue of vehicles that formed in front of the toll gate.

\subsection{Parameter FIFO queue discipline}

The following equations (5) - (8) can be used to compute n, q, d, and w for FIFO queuing disciplines.

$$
\begin{aligned}
& n=\frac{\lambda}{(\mu-\lambda)}=\frac{\rho}{(1-\rho)} \\
& q=\frac{\lambda^{2}}{\mu(\mu-\lambda)}=\frac{\rho^{2}}{(1-\rho)} \\
& d=\frac{1}{(\mu-\lambda)}
\end{aligned}
$$




$$
w=\frac{\lambda}{\mu(\mu-\lambda)}=d-\frac{1}{\mu}
$$

Where:

$\begin{array}{ll}\mathrm{n} & =\text { number of vehicles or people in the system (vehicle or person per unit of time) } \\ \mathrm{q} & =\text { number of vehicles or people in the queue (vehicle or person per unit time) } \\ \mathrm{d} & =\text { time of vehicle or person in the system (unit time) } \\ \mathrm{W} & =\text { time of vehicle or person in queue (unit time) } \\ \lambda & =\text { average arrival rate } \\ \mu & =\text { average service levels } \\ \rho & =\text { traffic intensity or usage factor }=\frac{\lambda}{\mu}\end{array}$

\subsection{VISSIM Program (visual simulation)}

VISSIM is a microscopic software that serves to simulate urban traffic models and public transport operations.

This program can analyze traffic and displacements with modeling constraints such as path geometric, vehicle composition, traffic signals, stop line, driver behavior and others, Making it a useful tool for evaluating alternatives based on transport engineering as more effective and efficient decision-making steps in planning activities including simulations in the development of modes [5].

\section{Research methodology}

\subsection{Primary data collection}

Primary data collection is done at the entrance of the Amplas toll road. The survey was conducted by recording video on traffic activity at the research location. The survey was conducted by placing a video camera placed on a spot that could include the toll entrance area. The survey was conducted on Wednesday, June 7, 2017 at $07.00-12.00$ WIB. The data obtained while conducting the survey are:

1. The volume of the vehicle leading to the toll booth where in this case is done by recording using a handycam. Then manually calculated the number of vehicles coming every 1 minute.

2. The speed of the vehicle leading to the toll booth. The speed of the vehicle is calculated by using Spot Speed method is the recording time travel of vehicles passing through the road segment of observation. Recording time travel is done by turning on the stopwatch just as the front wheel of the vehicle passes the first step of the trail following the vehicle's lane and the stopwatch is switched off to the wheel of the vehicle over the second stampede line.

3. Service time at each toll booth. Conducted when the vehicle stops in front of the substation (counter) to signify the transaction (when toll payment is in progress) until the vehicle moves to leave the substation. Service time is calculated using stopwatch

This research is done through several stages of the process. The above stages can be seen in the following figure of flow chart. 


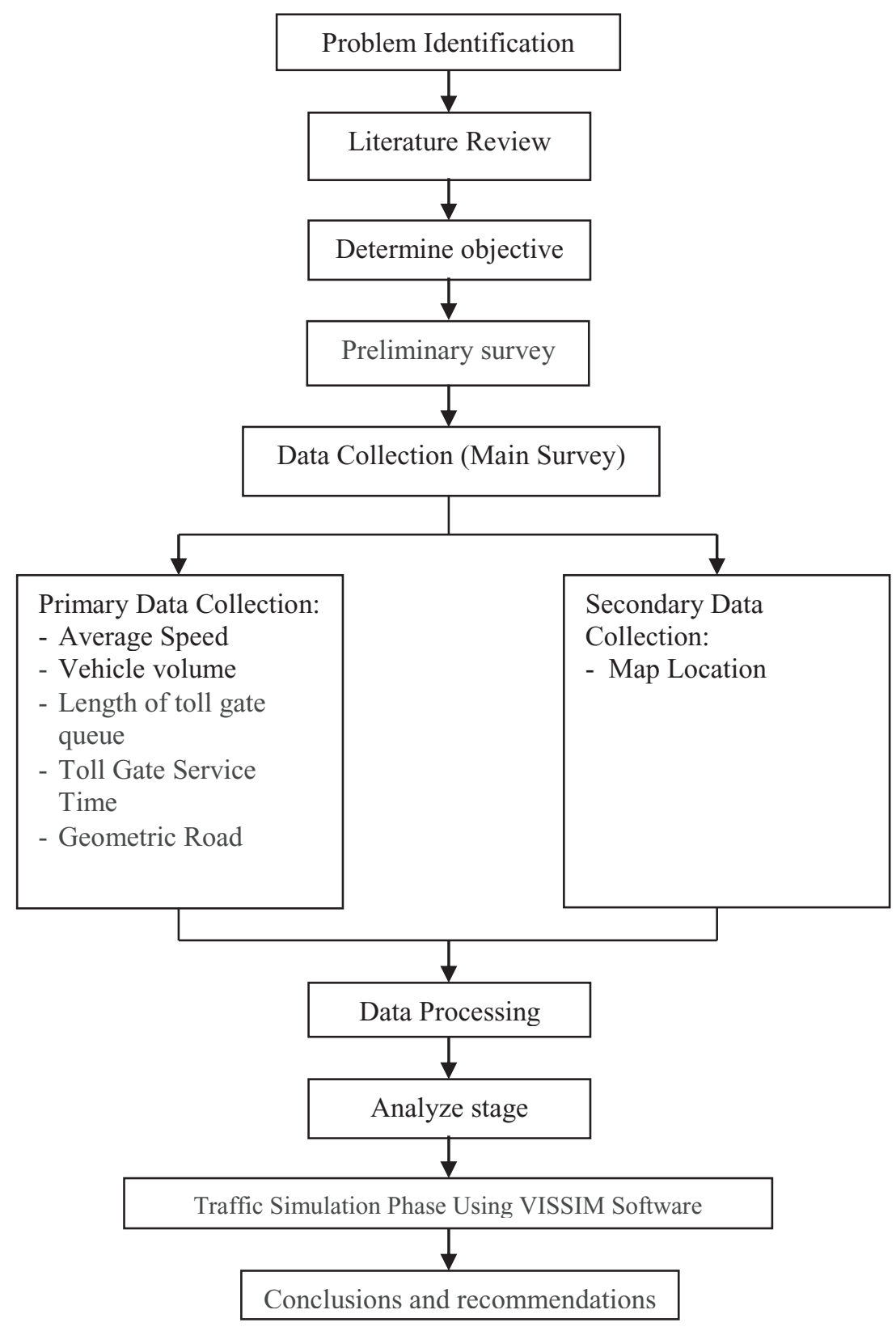

Fig. 1. Flow chart

\section{Analysis and discussion}

\subsection{Calculation of arrival Rate}

Average vehicle arrival $(\lambda)$

$$
\lambda=\frac{\Sigma \mathrm{x}}{N}=\frac{4698}{5}=939,6 \approx 940 \text { vehicle } / \text { hour }
$$


Table 1. Survey data of arrival level of Amplas Toll Gate

\begin{tabular}{|c|c|c|}
\hline No & Hour (WIB) & Number of vechiles \\
\hline 1 & $07.00-08.00$ & 973 \\
\hline 2 & $08.00-09.00$ & 1004 \\
\hline 3 & $09.00-10.00$ & 965 \\
\hline 4 & $10.00-11.00$ & 919 \\
\hline 5 & $11.00-12.00$ & 837 \\
\hline \multicolumn{2}{|c|}{ Total } & 4698 \\
\hline
\end{tabular}

\subsection{Calculation of service level}

Table 2. Data on service time average of Amplas Toll Gate

\begin{tabular}{|c|c|}
\hline Substasion & Average Service Time (seconds) \\
\hline 1 & 6,73 \\
\hline 2 & 6,82 \\
\hline 3 & 7,34 \\
\hline Mean & 6,96 \\
\hline
\end{tabular}

The average service level of substations $(\mu)$

$$
\mu=\frac{3600}{7}=517,2 \approx 517 \text { vehicle/ hour }
$$

\subsection{Capacity Calculation of Amplas Toll Gate}

$\rho=\frac{940 / 3}{517}=0,60>1$

With a value of $\rho>1$, the Amplas Tollgate can still accommodate the number of vehicles coming.

\subsection{Calculation of queue length with queue theory}

Using with $\mathrm{ST}=7$ second/vehicle

$\mu=515 ; \lambda=940 ; N=3$

$n=\frac{940 / 3}{515-(940 / 3)}=1,553=2$ vehicles

$q=\frac{(940 / 3)^{2}}{515(515-(940 / 3))}=0,945=1$ vehicles

$d=\frac{1}{515-(940 / 3)} \times 3600=17,851=18$ seconds

$w=\frac{(940 / 3)}{515(515-(940 / 3))} \times 3600=10,860=11$ seconds 
Table 3. Calculation of queue length with combination of service time

\begin{tabular}{|c|c|c|c|c|c|c|c|}
\hline ST & $\begin{array}{c}\text { Service Rate } \\
\text { (vehicle/hour) }\end{array}$ & $\begin{array}{c}\text { Number } \\
\text { of } \\
\text { vehicles } \\
\text { queuing } \\
\text { up } \\
\text { (vehicle) }\end{array}$ & $\begin{array}{c}\text { Length } \\
\text { of } \\
\text { queue } \\
(\mathrm{m})\end{array}$ & $\begin{array}{c}\text { Number } \\
\text { of } \\
\text { vehicles } \\
\text { queuing } \\
\text { up } \\
\text { (vehicle) }\end{array}$ & $\begin{array}{c}\text { Length } \\
\text { of } \\
\text { queue }\end{array}$ & $\begin{array}{c}\text { Waiting } \\
\text { time } \\
\text { (second) }\end{array}$ & $\begin{array}{c}\text { Waiting } \\
\text { time } \\
\text { (second) }\end{array}$ \\
\hline 7 & $\mu$ & $\mathrm{n}$ & $\mathrm{n}$ & $\mathrm{q}$ & $\mathrm{q}$ & $\mathrm{d}$ & $\mathrm{W}$ \\
\hline 8 & 515 & 1.553 & 6.212 & 0.945 & 3.78 & 17.851 & 10.86 \\
\hline 9 & 450 & 2.292 & 9.168 & 1.596 & 6.384 & 26.341 & 18.341 \\
\hline 10 & 360 & 3.615 & 14.46 & 2.832 & 11.328 & 41.538 & 32.538 \\
\hline 11 & 328 & 6.714 & 26.856 & 5.843 & 23.372 & 77.142 & 67.142 \\
\hline 12 & 300 & -21.363 & 85.452 & 20.408 & 81.632 & 245.454 & 234.478 \\
\hline
\end{tabular}

where,

$\mathrm{n}-\mathrm{q}=1 ; \mathrm{d}-\mathrm{w} \quad=$ service time

1 vehicle $\quad=4$ meters

Minus sign (-) = there is a queue that will continue to grow long (infinity)

\subsection{Calculation of queue length with VISSIM Software}

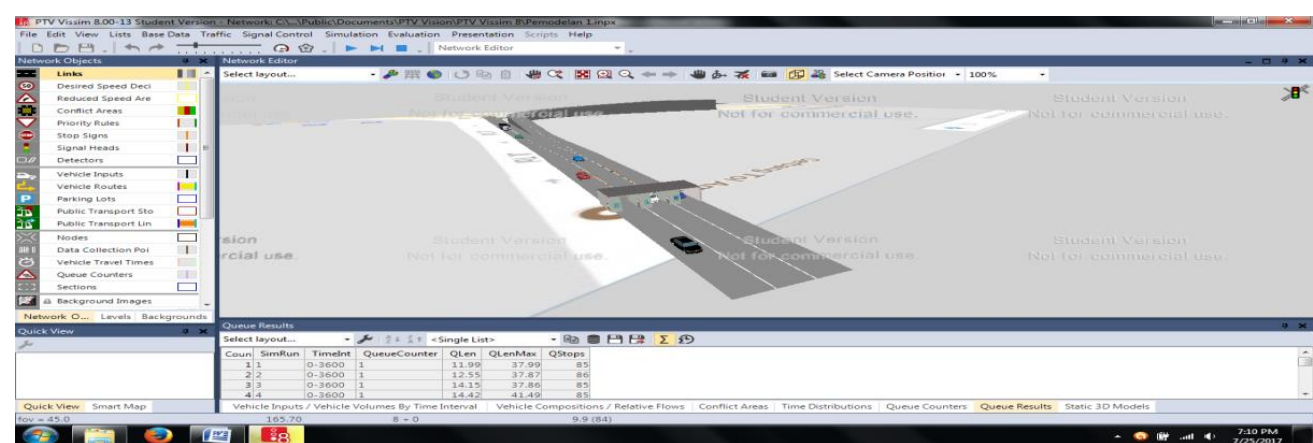

Fig. 2. Simulation of Amplas Toll Door after ramp off development

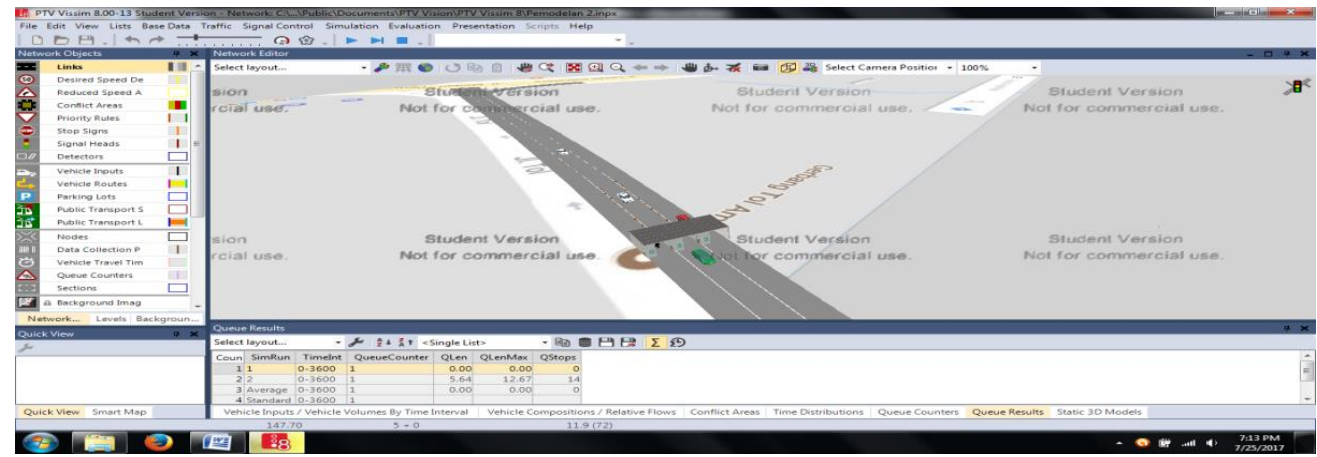

Fig. 3. Simulation of Amplas Toll Gate before ramp off development

After running the simulation, a new queue length is generated based on the output. The output of the queue length can be seen in Table 4 and Table 5. 
Table 4. Queue Length of Amplas Toll Door after ramp off development

\begin{tabular}{|c|c|c|c|c|c|}
\hline NO & $\begin{array}{c}\text { Service } \\
\text { Time }\end{array}$ & Time Interval & $\begin{array}{c}\text { Minimum } \\
\text { Queue } \\
\text { length } \\
\text { (meter) }\end{array}$ & $\begin{array}{c}\text { Maximum } \\
\text { Queue Length } \\
\text { (meter) }\end{array}$ & $\begin{array}{c}\text { Vehicle stop } \\
\text { (Vehicle) }\end{array}$ \\
\hline 1 & 7 seconds & $0-3600$ & 11.98803 & 37.990954 & 85 \\
\hline 2 & 8 seconds & $0-3600$ & 12.5477 & 37.869336 & 86 \\
\hline 3 & 9 seconds & $0-3600$ & 14.1493 & 37.858121 & 85 \\
\hline 4 & 10 seconds & $0-3600$ & 14.42131 & 41.486207 & 85 \\
\hline 5 & 11 seconds & $0-3600$ & 15.93987 & 44.875732 & 85 \\
\hline
\end{tabular}

Table. 5. Queue Length of Amplas Toll Door Before Ramp Off Development

\begin{tabular}{|c|c|c|c|c|c|}
\hline NO & $\begin{array}{c}\text { Service } \\
\text { Time }\end{array}$ & Time Interval & $\begin{array}{c}\text { Minimum } \\
\text { Queue } \\
\text { length } \\
\text { (meter) }\end{array}$ & $\begin{array}{c}\text { Maximum } \\
\text { Queue Length } \\
\text { (meter) }\end{array}$ & $\begin{array}{c}\text { Vehicle stop } \\
\text { (Vehicle) }\end{array}$ \\
\hline 1 & 7 seconds & $0-3600$ & 6.674095 & 14.817103 & 78 \\
\hline 2 & 8 seconds & $0-3600$ & 7.37283 & 20.981991 & 78 \\
\hline 3 & 9 seconds & $0-3600$ & 8.193706 & 25.884951 & 81 \\
\hline 4 & 10 seconds & $0-3600$ & 8.87812 & 20.341288 & 80 \\
\hline 5 & 11 seconds & $0-3600$ & 10.15851 & 23.510463 & 81 \\
\hline
\end{tabular}

Based on VISSIM software modeling results obtained that the length of the queue tollgate Amplas after the construction of ramp-off increases compared to before the rampoff. The queue length increased from 6.67 meters to 11.98 meters.

\subsection{Analysis of the effectivenes of the queue length reduction policy}

Polict taken:

- Increase the number of toll booths (from 3 substations to 4 substations)

- Apply "Gerbang Tol Manual” (GTO)

\subsection{Addition of toll gate}

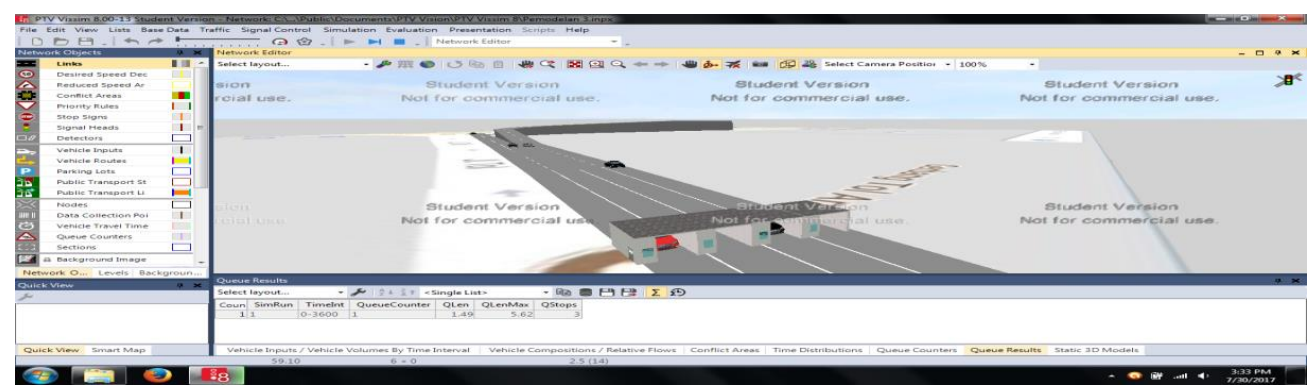

Fig. 4. Simulation of Amplas Toll Gate with 4 toll gate

Simulated with VISSIM software by inputting the same number of vehicles and service time and adding the number of toll booths to 4 pieces. After running the simulation, a new queue length is generated.Comparison of queue length results can be seen in table 6 . 
Table 6. Comparative Length of Toll Gate Door Amplas 3 Gardu and 4 Gardu

\begin{tabular}{|c|c|c|c|c|c|}
\hline \multirow{2}{*}{ No } & \multirow{2}{*}{$\begin{array}{c}\text { Time } \\
\text { Service }\end{array}$} & \multicolumn{4}{|c|}{ Queue Length (meters) } \\
\cline { 3 - 6 } & & 3 substaion & \multicolumn{2}{c|}{ 3 Substation } \\
\cline { 3 - 6 } & & Queue Theory & $\begin{array}{c}\text { VISSIM } \\
\text { Software }\end{array}$ & Queue Theory & VISSIM Software \\
\hline 1 & 7 seconds & 6.212 & 11.988028 & 3.356 & 7.559299 \\
\hline 2 & 8 seconds & 9.168 & 12.547704 & 4.372 & 8.085288 \\
\hline 3 & 9 seconds & 14.46 & 14.149299 & 5.696 & 9.274755 \\
\hline 4 & 10 seconds & 26.856 & 14.421311 & 7.52 & 10.656138 \\
\hline 5 & 11 seconds & 85.452 & 15.939865 & 10.104 & 12.122563 \\
\hline
\end{tabular}

\subsection{Application of GTO System}

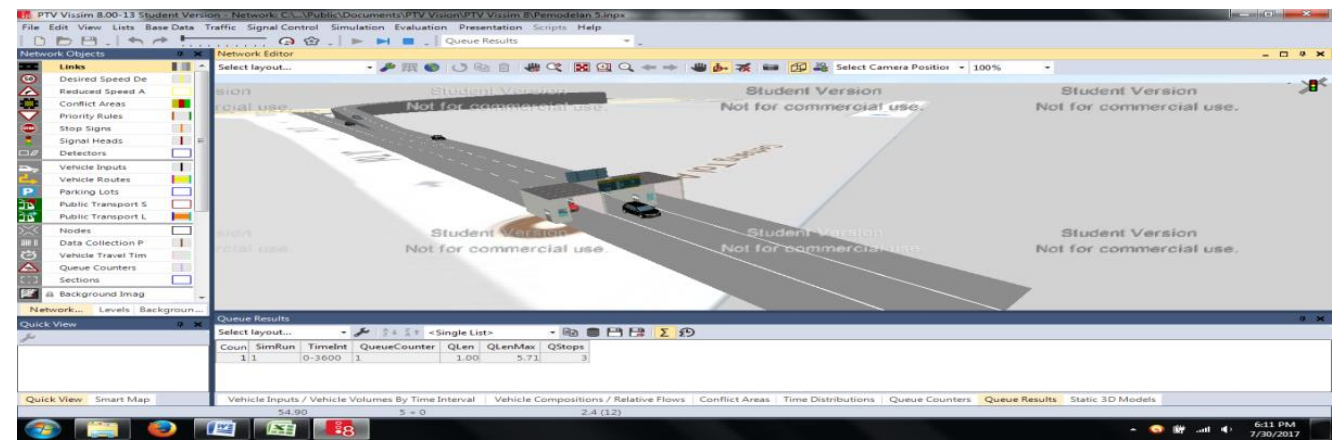

Fig. 5. Simulation of Amplas Toll Gate with GTO System

Conducted simulation with VISSIM software by applying 1 tollgate transformed into a GTO system with the assumption of time used by the driver of 3 seconds. After running the simulation, a new queue length is generated. Comparison of queue length results can be seen in table 7.

Table 7. Comparative length of Toll Gate Amplas Door with GTO System

\begin{tabular}{|c|c|c|c|c|}
\hline \multirow{2}{*}{ No } & \multirow{2}{*}{$\begin{array}{c}\text { Time } \\
\text { Serive }\end{array}$} & $\begin{array}{c}\text { Queue } \\
\text { Theory }\end{array}$ & $\begin{array}{c}\text { VISSIM Software without } \\
\text { GTO }\end{array}$ & $\begin{array}{c}\text { VISSIM software with } \\
\text { GTO system }\end{array}$ \\
\hline 1 & 7 seconds & 6.212 & 11.988028 & 9.437607 \\
\hline 2 & 8 seconds & 9.168 & 12.547704 & 9.626659 \\
\hline 3 & 9 seconds & 14.46 & 14.149299 & 9.667078 \\
\hline 4 & 10 seconds & 26.856 & 14.421311 & 10.056292 \\
\hline 5 & 11 seconds & 85.452 & 15.939865 & 10.428499 \\
\hline
\end{tabular}

\section{Conclusions and recommendation}

\subsection{Conclusions}

1. Based on the results of the survey conducted obtained the volume of vehicles at the substation entrance of the toll gate Amplas of 940 vehicles / hour with an average WP 6.96 seconds 
2. Based on the calculation, for the current condition of service time 7 seconds obtained value service level at the toll gate of Amplas of 515 vehicles / hour / substation while the arrival of each substation of 313 vehicles / hour / substation.

3. Based on the results of queue length analysis with the average service time of 7 seconds, obtained the length of queue with queue theory analysis of 6.12 meters while the results of VISSIM modeling software queue length of 11.98 meters.

4. Based on the results of VISSIM software modeling it is found that the length of the queue tollgate quota after the build up of ramp-off increases compared to before the ramp-off. Before the ramp-off was built the queue length of 6.67 meters while after the ramp-off built the queue length to 11.98 meters.

5. In an effort to minimize the values of $\mathrm{n}, \mathrm{q}, \mathrm{d}$, and $\mathrm{w}$, it can be concluded that the priority order of policy-making is the first policy implementation of GTO system and the second priority is the policy of adding toll gate.

\section{Recommendation}

To anticipate the increase of vehicle volume, the improvement of quality that can be done is the addition of toll substations to 4 pieces of toll booths or the implementation of the GTO system on one of the toll booths.

\section{References}

1. Departemen PU DirJen Bina Marga. Geometri Jalan Bebas Hambatan untuk Jalan Tol, Departemen PU DirJen Bina Marga. (2009)

2. Departemen PU DirJen Bina Marga. Manual Kapasitas Jalan Indonesia (MKJI) 1997. Departemen PU DirJen Bina Marga. (1997).

3. Currin Thomas R. Traffic Engineering A Manual for Data Collection and Analysis. USA:Brooks/Cole. (1950)

4. Cahyani, Rezky D N dkk. Analisis Kapasitas Dan Tingkat Layanan Pada Gerbang Tol Cikarang Utama, Universitas Indonesia. Jakarta. (2013)

5. Hilmy, Ahmad and Hamid, Abdul. Simulation of Traffic Operation and Management at Malaysian Toll Plazas using VISSIM, Universitas Sains Malaysia. Malaysia.

6. Hobbs, F D. Traffic Planning and Engineering, University of Birmingham. Inggris. (1979)

7. Hutahaean, Marthyn. Evaluasi Kapasitas dan Pelayanan Gerbang Tol Tanjung Morawa, Universitas Sumatera Utara. Medan. (2007) 